\title{
Erratum to: What are the Parenting Experiences of Fathers? The Use of Household Survey Data to Inform Decisions About the Delivery of Evidence-Based Parenting Interventions to Fathers
}

\author{
Matthew R. Sanders • Cassandra K. Dittman • \\ Louise J. Keown $\cdot$ Sue Farruggia $\cdot$ Dennis Rose
}

Published online: 17 October 2014

(c) Springer Science+Business Media New York 2014

Erratum to: Child Psychiatry Hum Dev (2010) 41:562-581

DOI 10.1007/s10578-010-0188-z

Conflict of interest The Triple P-Positive Parenting Program is owned by the University of Queensland (UQ). The University through its main technology transfer company UniQuest Pty Limited has licensed Triple P International Pty Ltd to disseminate the program worldwide. Royalties stemming from this dissemination activity are distributed to the Parenting and Family Support Centre, School of Psychology, UQ; Faculty of Health and Behavioural Sciences at UQ; and contributory authors. No author has any share or ownership in Triple P International Pty Ltd. Matthew Sanders is the founder and an author on various Triple $\mathrm{P}$ programs and a consultant to Triple $\mathrm{P}$ International.

The online version of the original article can be found under doi:10.1007/s10578-010-0188-z.

M. R. Sanders $(\square)$

Parenting and Family Support Centre, The University of Queensland, Brisbane, QLD 4072, Australia

e-mail: matts@psy.uq.edu.au

C. K. Dittman - L. J. Keown - S. Farruggia - D. Rose

University of Auckland, Auckland, New Zealand 